\title{
PERSPECTIVES
}

\section{The Academic Quilting Bee}

\author{
Anita P. Mayer, $M D^{7}$, Julia A. Files, $M D^{2}$, Marcia G. Ko, $M D^{2}$, and Janis E. Blair, $M D^{3}$ \\ 'Division of Community Internal Medicine, Mayo Clinic, Scottsdale, AZ, USA; 'Division of Mayo Clinic Women's Health Internal Medicine, Mayo \\ Clinic, Scottsdale, AZ, USA; ${ }^{3}$ Division of Infectious Diseases, Mayo Clinic, Scottsdale, AZ, USA.
}

In medicine, the challenges faced by female faculty members who are attempting to achieve academic advancement have been well described. Various strategies have been proposed to increase academic productivity to aid the promotion of women in medicine. We propose an innovative collaboration strategy that encourages completion of an academic writing project. This strategy acknowledges the challenges inherent in achieving work-life balance and utilizes a collaborative work style with a group of peer physicians. The model is designed to encourage the completion and collation of independently prepared sections of an academic paper within a setting that emphasizes social networking and collaboration. This approach has many similarities to the construction of a quilt during a "quilting bee."

KEY WORDS: academic medical centers; career mobility; medical faculty; mentor; women physicians.

J Gen Intern Med 24(3):427-9

DOI: $10.1007 / \mathrm{s} 11606-009-0905-0$

(c) Society of General Internal Medicine 2009

\section{INTRODUCTION}

Women are entering academic medicine in larger numbers than ever before, yet they do not advance academically as a group at the same rate as their male counterparts ${ }^{1-3}$. The challenges faced by female faculty members seeking academic advancement are well described in the medical literature; these include the demands of clinical practice, the lack of collegial support, achieving work-life balance, the lack of mentoring, and other factors ${ }^{4-8}$.

Several years ago, we designed a facilitated peer mentoring program to address the lack of mentoring identified by our women faculty ${ }^{9}$. In our program, women faculty of similar academic rank self-identify and collaborate with two or three female colleagues who have an interest in participating in a mentoring program to facilitate academic advancement ${ }^{10}$. The self-identified members of the participating peer group have common academic interests and goals. The process of collaborative scientific writing and publishing is a key element of our program.

Received September 11, 2008

Revised December 23, 2008

Accepted January 5, 2009

Published online January 27, 2009
The need for adequate mentoring and the desire to work collaboratively are not unique to women; however, the model of women working together in social networks to produce a collective work does have historical roots. One of the more engaging examples is that of the "quilting bee". The purpose of the bee in earlier times was to bring together a group of women to socialize, support one another, and collaboratively complete a quilt.

The symbolism of the quilt itself is powerful. Small blocks of often intricately pieced work are bound together to produce a useful and practical household item or gift. Considering this model of a social network to produce a collective work through mutual support in a collegial climate, we designed and herein present the academic exercise we organized as an "academic quilting bee" conducted within the context of a social gathering.

\section{GENESIS OF THE ACADEMIC QUILTING BEE}

The facilitated peer mentoring program is designed to assist women at the instructor or assistant professor level who need to improve and hone the skills necessary for academic advancement. The early focus of the program is on the process of scientific writing ${ }^{10}$.

One of our peer mentoring groups, with three members working on a collaborative writing project, had encountered difficulty in completing a manuscript. One member of the peer group served as the lead author. Lead authorship responsibilities included selecting a topic, outlining the manuscript, and creating the preliminary draft. The lead author then assigned herself and each peer a different portion of the manuscript for further reference verification, editing, and refinement of the written section.

At this point, final completion of the paper became stalled. The group found it difficult to reach consensus on the paper, because they could not find sufficient time to work together to finalize the manuscript. This particular group believed that they were more productive when they could dedicate a large block of time to complete a project, yet large blocks of uninterrupted time were virtually impossible to schedule for them as a group.

The peer mentoring model provides facilitator-mentors to work with each group of peer mentors ${ }^{11}$. To provide the group with a block of uninterrupted time, the facilitator-mentors proposed the quilting bee to the peer group as a method to facilitate completion of their manuscript in a timely and efficient manner. The stated goal was to combine the individ- 
ually prepared sections of the manuscript into a cohesive whole, to revise and edit the first draft as a group, and to subsequently submit the manuscript electronically to the editorial support service at our institution. The plan was to complete these tasks by the end of the 4-hour quilting bee.

\section{ELEMENTS OF A SUCCESSFUL ACADEMIC QUILTING BEE}

As facilitators, our first task was to identify and address both the barriers to participation and the elements needed to ensure success. For this first quilting bee, important elements to address were an uninterrupted block of time and child care, as well as one-on-one mentoring and group mentoring.

We decided to conduct the quilting bee on a Friday evening after clinical responsibilities were finished. This day and time provided a large uninterrupted period in which to work. A 4-hour agenda was proposed; however, all the participants understood that the amount of time required to complete the project might exceed this estimated time frame. Child care was provided off site for group members who needed it. A comfortable work environment was provided. Each participant had access to the Internet, e-mail, an online medical library, and reference management software. A meal, snacks, and caffeinated beverages were also provided. This was an inexpensive event because the facilitators' teenage daughters provided safe, free child care, and the facilitators themselves provided the food.

Before the night of the quilting bee, each author had completed a previously assigned section. With their sections in hand, the author participants were paired with a facilitatormentor. A specific set of tasks was assigned to each pair. Working separately from the rest of the group, each pair reviewed and refined their section of the manuscript while adhering to the proposed timeline. The sections of the manuscript were then exchanged for content review, clarification, editing, and reference checking by another pair of authors. The sections were then combined into a final draft, which was reviewed in detail by all the participants.

\section{RESULTS}

During our quilting bee, three junior faculty authors and four senior faculty members who served as facilitators-mentors constructed a final draft of a manuscript from prewritten components. The project was completed in 6 hours, including time for eating and socializing, which exceeded the planned timeline by 2 hours. The participants indicated that the social context of the evening contributed considerably to their enthusiasm for the work and to their success in completing the manuscript. They also reported that they felt supported by the mentoring group effort and were relieved to know that their concerns about child care were being addressed.

\section{DISCUSSION}

Considerable discussion and various efforts have focused on attempts to increase the number of women in medicine who advance in academic $\operatorname{rank}^{1,12-14}$. Nonetheless, as women physicians try to balance the demands of an academic career with the demands they face in their personal lives, some drop out of the workforce or postpone their academic goals, whereas others struggle to find a way to stay on $\operatorname{track}^{4}$. The phenomenon of women slowing down or abandoning some or all of their career goals is not unique to medicine ${ }^{15}$. However, encouraging women to stay in and succeed in academic medicine may require creative and unique strategies.

Our quilting bee was designed to address the obstacles confronting a group of women who were attempting to complete their first manuscript as a scientific writing group. Although all of the authors were committed to completing the manuscript, they had been unable to do so because of scheduling issues and the need for child care. In our experience, the academic quilting bee works best for multiauthored papers that are nearing completion and need to be finalized. It does require the lead and collaborating authors to have completed their assigned tasks. We suggest that the completion of assigned tasks be verified before the academic quilting bee is scheduled. Our group attributed their success in this one well-defined project largely to the supportive and encouraging atmosphere of the evening.

This particular peer group has remained together for more than a year since the completion, submission, and acceptance of that first manuscript by a peer-reviewed journal. They subsequently completed a second manuscript and prepared a resident rotation curriculum and a research protocol, while also maintaining busy clinical practices and, of course, balancing family and personal demands.

Our decision to name our scientific writing project "The Academic Quilting Bee," incorporating a name commonly identified with a traditional women's domestic activity, and to write about it, has been carefully considered. It is not intended to marginalize women or give them "special" consideration. A collaborative writing project such as we have described may be equally applicable and important for all medical staff, as both men and women struggle to balance the demands of work and home. Finally, it is not presented as "the" answer to academic advancement for women in medicine. It was, for us, just a simple strategy that achieved its purpose, successful completion of the manuscript. Whether members of this or any other group will achieve a successful academic career within a scientific writing group launched by such a project remains to be determined.

Conflict of Interest: None disclosed.

Corresponding Author: Anita P. Mayer, MD; Division of Community Internal Medicine, Mayo Clinic, 13400 East Shea Boulevard, Scottsdale, AZ 85259, USA (e-mail: mayeranita@mayo.edu).

\section{REFERENCES}

1. McGuire LK, Bergen MR, Polan ML. Career advancement for women faculty in a U.S. school of medicine: perceived needs. Acad Med. 2004;79 (4):319-25, Apr.

2. Jagsi R, Guancial EA, Worobey CC, et al. The "gender gap" in authorship of academic medical literature: a 35-year perspective. N Engl J Med. 2006;355(3):281-7, Jul 20.

3. Nattinger AB. Promoting the career development of women in academic medicine. Arch Intern Med. 2007;167(4):323-4, Feb 26. 
4. Nonnemaker L. Women physicians in academic medicine: new insights from cohort studies. N Engl J Med. 2000;342(6):399-405, Feb 10.

5. Blair JE, Files JA. In search of balance: medicine, motherhood, and madness. J Am Med Womens Assoc. 2003;58(4):212-6, Fall.

6. Fried LP, Francomano CA, MacDonald SM, et al. Career development for women in academic medicine: multiple interventions in a department of medicine. JAMA. 1996;276(11):898-905, Sep 18.

7. Carr PL, Ash AS, Friedman RH, et al. Relation of family responsibilities and gender to the productivity and career satisfaction of medical faculty. Ann Intern Med. 1998;129(7):532-8, Oct 1.

8. Yedidia MJ, Bickel J. Why aren't there more women leaders in academic medicine? the views of clinical department chairs. Acad Med. 2001;76 (5):453-65, May.

9. Mayer AP, Blair JE, Files JA. Peer mentoring of women physicians. J Gen Intern Med. 2006;21(9):1007, Sep.
10. Files JA, Blair JE, Mayer AP, Ko MG. Facilitated peer mentorship: a pilot program for academic advancement of female medical faculty. J Womens Health (Larchmt). 2008;17(6): 1009-15, Jul-Aug.

11. Blair JE, Mayer AP, Ko MG, Files JA. Facilitated peer mentorship: the challenges faced by facilitator-mentors. Clin Teach. 2008;5(3): 133-7, Sep.

12. Bickel J, Wara D, Atkinson BF, et al. Increasing women's leadership in academic medicine: report of the AAMC Project Implementation Committee. Acad Med. 2002;77(10):1043-61, Oct.

13. Hamel MB, Ingelfinger JR, Phimister E, Solomon CG. Women in academic medicine: progress and challenges. N Engl J Med. 2006;355 (3):310-2, Jul 20

14. Jagsi R, Butterton JR, Starr R, Tarbell NJ. A targeted intervention for the career development of women in academic medicine. Arch Intern Med. 2007;167(4):343-5, Feb 26.

15. Hewlett SA, Luce CB. Off-ramps and on-ramps: keeping talented women on the road to success. Harv Bus Rev. 2005;83(3):43-6, 48, 50-4, Mar. 